\title{
A NEGOCIAÇÃO COLETIVA COMO INSTRUMENTO DA EFETIVAÇÃO DA IGUALDADE MATERIAL
}

\section{COLLECTIVE NEGOTIATION AS AN INSTRUMENT FOR THE EFFECTIVENESS OF MATERIAL EQUALITY}

\author{
MOTTA, Ivan Dias da ${ }^{1}$ \\ BARACAT, Eduardo Milléo ${ }^{2}$ \\ RODRIGUES, Tiago Fogaça ${ }^{3}$
}

\section{RESUMO}

Busca-se neste artigo, por meio de revisão bibliográfica e análise documental, descobrir se a negociação coletiva tem permitido a efetivação da igualdade de gênero nas negociações realizadas pelo Sindicato dos Professores no Estado do Paraná que vigeram durante o ano de 2019. Para tanto, define-se a igualdade, formal e material, e apresentase a discriminação em razão do gênero. Após, demonstra-se que a negociação coletiva pode ser usada como instrumento de efetivação da igualdade material entre trabalhadores e trabalhadoras, bem como, combate à discriminação. Por fim, apresentase o resultado das análises das negociações coletivas que vigeram durante o ano de 2019 no Sindicato dos Professores no Estado do Paraná, sendo que, a partir dos conceitos teóricos, são identificadas cláusulas dos acordos ou convenções coletivas que contribuem para a efetivação da igualdade material entre trabalhadores e trabalhadoras. Como resultado do trabalho, identifica-se que esse sindicado ainda é incipiente em suas conquistas para a classe, mas estão presentes cláusulas que permitem, ainda que indiretamente, a efetivação da igualdade.

\footnotetext{
${ }^{1}$ Possui graduação em Direito pela Universidade Estadual de Maringá (1996), mestrado em Direito das Relações Sociais pela Pontifícia Universidade Católica de São Paulo (1998) e doutorado em Direito das Relações Sociais pela Pontifícia Universidade Católica de São Paulo (2000), Pós-doutorado em Direito Educacional pela Pontifícia Universidade Católica de São Paulo (2001). Atualmente é professor permanente do Programa de Mestrado em Direito do Centro Universitário de Maringá, integrando a linha de pesquisa "A Tutela Constitucional e Privada dos Direitos da Personalidade nas Relações Privadas". Possui atuação profissional na área da advocacia e consultoria em Direito Educacional.

${ }^{2}$ Doutor em Direito das Relações Sociais pela Universidade Federal do Paraná (2002); Mestre em Direito Privado pela Universidade Federal do Paraná (1995); Diplôme Supérieur de 1'Université - Droit du Travail \& Sécurité Sociale pela Université Panthéon-Assas/Paris II (1998). Graduado em Direito pela Pontifícia Universidade Católica do Paraná (1987). Juiz Titular da $9^{a}$ Vara do Trabalho de Curitiba. Coordenador Pedagógico da Escola Judicial do Tribunal Regional do Trabalho da 9a Região. Professor Permanente do Programa de Mestrado em Direito Empresarial e Cidadania do UNICURITIBA. Realizou estágio Pós-Doutoral na Universidade de Coimbra (2016-2017). Tem experiência em: Direito do Trabalho. Relações Sociais. Empresa e Cidadania no universo do Direito do Trabalho

3 Mestrando em Direito Empresarial e Cidadania pelo Centro Universitário de Curitiba. Contato: tiago_tfr@hotmail.com
} 
Palavras-chave: Igualdade Material; Negociação Coletiva; Igualdade de gênero; Assédio Sexual; Discriminação em Razão do Sexo.

\begin{abstract}
This article seeks, through bibliographic review and documentary analysis, to find out if collective bargaining has enabled the realization of gender equality in the negotiations carried out by the Teachers' Union in the State of Paraná that were in effect during 2019. Therefore, equality is defined, formal and material, and discrimination based on gender is presented. Afterwards, it is shown that collective bargaining can be used as an instrument for the realization of material equality between male and female workers, as well as combating discrimination. Finally, the result of the analysis of collective bargaining that takes place during 2019 at the Teachers' Union in the State of Parana is presented, and from the theoretical concepts, clauses of collective agreements or conventions that contribute to the effective material equality between male and female workers. As a result of the work, it is identified that this union is still incipient in its achievements for the class, but clauses are present that allow, even if indirectly, the effectiveness of equality.
\end{abstract}

keywords: Equality Material; Collective Bargaining; Equality of Sex; Sexual harassment; Discrimination in Sex Reason.

\title{
INTRODUÇÃO
}

Busca-se analisar, no presente artigo, se a negociação coletiva tem permitido a efetivação da igualdade de gênero nos instrumentos coletivos firmados pelo Sindicato dos Professores no Estado do Paraná que vigeram durante o ano de 2019.

Historicamente, a mulher sofre obstáculos sociais para alcançar os mesmos postos de trabalho que os homens. Assim, com o objetivo de olhar para esse sério problema social, o presente artigo pretende contribuir com o debate sobre o tema, trazendo para a discussão a utilização das negociações coletivas como instrumentos para a efetivação da igualdade entre trabalhadores e trabalhadoras.

Portanto, por meio de revisão bibliográfica e análise das negociações coletivas que vigeram durante o ano de 2019, em que o Sindicato dos Professores no Estado do Paraná é parte, busca-se identificar cláusulas que possibilitem a efetivação da igualdade material entre ambos gêneros. 


\section{A IGUALDADE E A NÃO DISCRIMINAÇÃO}

É importante, em primeiro ponto, delimitar a igualdade, e na sequência, apresentar a sua relação com a proibição da discriminação de fato e com as medidas positivas que visem a igualdade de gênero nas relações de trabalho.

\subsection{A IGUALDADE FORMAL E A IGUALDADE MATERIAL}

A igualdade, para o direito, pode ser compreendida de mais de uma maneira. Dentre as possíveis compreensões acerca do tema, tem-se a da igualdade formal, que veio de um dos motes das Revoluções Burguesas do século XVIII. Essa igualdade consiste no estabelecimento de um tratamento paritário de todos perante a lei, ou seja, para a igualdade formal, todos devem ser tratados da mesma forma (PÉREZ LUÑO, 2007, p. 19).

O movimento conhecido como constitucionalismo liberal - constitucionalismo imediatamente pós Revolução Francesa - faz efundir esse conceito de igualdade como condição para a soberania popular. A lei, enquanto vontade geral, é a garantidora de que todos possam concorrer em igualdade de situação, fugindo da lógica estatal existente durante a Idade Média, em que a vontade do Estado estava subjugada aos interesses da aristocracia que, apesar de improdutiva, gozava de privilégios inalcançáveis pelas castas inferiores de uma sociedade estratificada. Essa nova lógica se justifica pela necessidade de se oferecer segurança jurídica no Estado, chamado então de Estado de Direito, que tem como requisitos objetivos a formulação adequada de normas no ordenamento jurídico e seu cumprimento pelos seus destinatários e por aqueles encarregados de sua aplicação (PÉREZ LUÑO, 2007, p. 20-22).

Nesse contexto, o princípio da igualdade formal, também chamado de princípio da igualdade perante a lei, presta-se a excluir, via de regra, a institucionalização de privilégios nas relações jurídicas. Assim, esse princípio se identifica com abstração de generalidade da norma jurídica, visto que ela deve ser tipificada em termos impessoais e universais para embasar sua subsunção e, portanto, para extrair suas consequências jurídicas. Essa generalidade da norma se fundamenta no direito natural de que a lei deveria ser dirigida à utilidade comum de todos, e não dos direitos privados. Hodiernamente, esse princípio também é evocado pela doutrina e pela jurisprudência para combater arbitrariedades legislativas, pois a igualdade formal, enquanto forma de 
abrangência da totalidade dos indivíduos, é entrelaçada aos princípios da legalidade e da segurança jurídica (PÉREZ LUÑO, 2007, p. 22-24).

Já o princípio da igualdade, enquanto equiparação, se propõe a enquadrar situações ou circunstâncias diferentes como semelhantes, com a finalidade de tratar com igualdade aquelas situações ou circunstâncias cujas diferenças não são relevantes ao ponto de afastar a mesma aplicação da regra. Corolário do princípio da igualdade formal, o que se busca é evitar a discriminação ou o privilégio ao se aplicar a norma abstrata ao caso concreto. Isso se justifica porque a igualdade nunca existirá na realidade, sendo sempre uma aproximação de objetos que apresentem traços ou características comuns (PÉREZ LUÑO, 2007, p. 24-25).

Nesse aspecto, pode-se dizer que o princípio da igualdade significa o estabelecimento de critérios de relevância entre as diferenças das situações. Em outras palavras é tratar com igualdade todas as situações cujas diferenças não são relevantes (PÉREZ LUÑO, 2007, p. 26). Poder-se-ia exemplificar esses critérios de relevância da seguinte forma: 1) tendo como premissa o artigo $7^{\circ}, \mathrm{XXX}$, da Constituição de 1988, em que se prevê a igualdade de salários para todos os trabalhadores, significa dizer que a previsão constitucional afirma serem irrelevantes as diferenças de sexo, idade, naturalidade, etc., para fins de estipulação do salário do trabalhador; 2) no mesmo raciocínio, ao se prever no artigo 10, II, "b" do Ato das Disposições Constitucionais Transitórias que a trabalhadora gestante possui estabilidade desde a confirmação da gravidez até cinco meses após o parto em decorrência da concepção de uma nova vida, significa afirmar que a diferença de sexo, nesse caso, é relevante para se diferenciar o trabalhador, que não possui o direito à essa estabilidade, da trabalhadora, que o possui independentemente da idade ou naturalidade, por exemplo; 3) como último exemplo, tem-se a previsão constitucional do artigo $7^{\circ}$, XXXIII, em que contém a proibição de trabalho noturno, perigoso e insalubre para menores de 18 anos, o que revela mais um estabelecimento de critério de relevância para as diferenças, que desta vez é a idade, pouco importando o sexo ou a naturalidade (BRASIL, 1988).

Logo, em conjunto com a generalidade e a equiparação, a diferenciação é um elemento do princípio da igualdade que previne a aplicação indistintamente da lei em diferentes situações. Trata-se de um complemento para que a aplicação do princípio da igualdade perante a lei ocorra com racionalidade. O princípio da igualdade aplicado desta forma diferencia-se daquela concepção estática da igualdade formal e pode ser exemplificado por meio da tipificação da tributação progressiva conforme a capacidade 
contributiva do contribuinte (PÉREZ LUÑO, 2007, p. 28-30) prevista no artigo 153, $\S 2^{\circ}$, I da Constituição de 1988 (BRASIL, 1988).

Dessa forma, o princípio da igualdade se concretiza na medida em que é possível, por meio de sua aplicação, satisfazer sua finalidade de definir critérios relevantes de igualdade ou diferença para a aplicação da igualdade enquanto postulado no caso concreto. Isso porque há elementos que podem ser extraídos dos casos, envolvendo pessoas ou situações, que estão diretamente ligados à finalidade da igualdade como ponto de partida, e por isso podem ser usados como justificativas para definição do quê, ou quem, é igual ou diferente. A aplicação desse princípio, em última análise, decorre da igualdade enquanto regra, ou seja, da vedação à discriminação (ÁVILA, 2003, p. 93-94).

Portanto, nesse campo do princípio da igualdade perante a lei, pode-se falar em igualdade material, pois a diferenciação se presta para compensar as diferenças históricas e sociais de marginalização de uma coletividade (PÉREZ LUÑO, 2007, p. 31). Frisa-se que a igualdade material significa a busca de uma igualdade real e efetiva entre os grupos sociais, apesar de suas diferenças econômicas e sociais. Essa busca pela igualdade material é objetivo do Estado Social, que, pode-se dizer de forma bastante superficial, é a evolução do Estado Liberal. O sentido das normas que preveem a igualdade material é o de corrigir eventuais desigualdades causadas no implacável cumprimento da igualdade formal (MARTINEZ, 2009, p. 34).

Contudo, a busca pela igualdade material não pode ser medida de exclusão ou anulação da igualdade formal. Elas não são incompatíveis. Mas ao contrário, a igualdade material deve ser aplicada quando há uma justificativa para o tratamento desigual frente à norma de igualdade formal. Essa justificativa está relacionada à impossibilidade de se estabelecer uma igualdade real no caso concreto apenas com a aplicação da igualdade formal. Portanto, a permissão para a discriminação, chamada de ação positiva, é fundada na igualdade material (MARTINEZ, 2009, p. 35).

Isso posto, parte-se da premissa de que a igualdade material deve ser buscada como forma de combater as desigualdades.

\subsection{AÇÕES POSITIVAS PARA COMBATER A DISCRIMINAÇÃO}

Para melhor aclarar o que seria essa ação positiva fundada na igualdade material, pode-se exemplificar com a vedação da discriminação prevista no artigo $5^{\circ}$ da Constituição de 1988 em que se prevê a igualdade de tratamento para todos. Assim, por 
exemplo, a contratação de trabalhadores por uma empresa deveria ocorrer de forma isonômica, ou seja, seria vedado o estabelecimento de diferenças de sexo, idade, naturalidade, etc. para fins de contratação dos trabalhadores (BRASIL, 1988). Entretanto, em razão de diferenças historicamente arraigadas na coletividade, como também por exemplo a diferença social em que há predominância de negros nas classes mais baixas da sociedade, provavelmente em decorrência da escravização dos povos africanos, instaura-se uma discriminação de fato, pois esse estigma entorno dos negros acaba prejudicando o acesso deles ao emprego. Assim, ao se criar uma norma protetiva desse grupo, em que se vislumbrasse a garantia de uma cota das ofertas de vagas para negros, garantir-se-ia que não houvesse uma discriminação de fato na contratação.

A ideia que se busca trazer em evidência é que a vedação de uma discriminação negativa, que exclui ou marginaliza determinados grupos, gera uma discriminação positiva, que inclui os grupos marginalizados, pois a realidade histórica, social ou econômica, pode demonstrar a necessidade de se estabelecer critérios diferenciadores para se atingir uma igualdade real entre os grupos sociais (MARTINEZ, 2009, p. 36-38).

Portanto, o que se pode verificar é que a igualdade material é medida corretiva das desigualdades de fato produzidas pela aplicação da igualdade formal, ou seja, é a busca pela não discriminação de fato. Uma dessas desigualdades de fato, que ainda assombram a contemporaneidade, é a de gêneros.

\subsection{A (DES)IGUALDADE DE GÊNERO NO AMBIENTE DE TRABALHO}

Convém trazer a luz que, desde a colonização brasileira, a mulher sempre compôs a massa de mão de obra, sobretudo as mais pobres e as escravas. Entretanto, o modelo de família patriarcal, que exercia seu poder e influência no Estado, na Igreja e outras instituições sociais e econômicas, contribuiu de forma decisiva para manter o papel da mulher na sociedade como coadjuvante e o do homem como protagonista, influenciando inclusive nas liberdades pessoais da mulher, como a sexual (GEARA; BOTH, 2016, p. 108-112).

Foi com o enfraquecimento do modelo familiar patriarcal, na segunda metade do século XIX, que a mulher se viu diante de uma abertura de oportunidades no mercado de trabalho, porém ainda restrita às áreas burocráticas e industriais. É importante frisar que havia uma diferença de gênero, em prejuízo das mulheres, instaurada na sociedade, que limitava suas liberdades, ao ponto do Código Civil de 1916 
limitar o acesso da mulher ao emprego e à propriedade. Somente a partir da década de 60 do século XX é que a mulher se viu mais valorizada socialmente. Nesta época já não se exigia a autorização marital para assinar o contrato de trabalho, entrou em vigor o Estatuto da Mulher Casada e o acesso da mulher à educação foi facilitado. Somente nesse período a mulher passou a ocupar cargos na área da medicina, advocacia, odontologia, cargos públicos, etc. Em 2009, a mulher já representava 49,7\% da população ativa brasileira (GEARA; BOTH, 2016, p. 113-116). Porém, é importante ainda se demonstrar os reflexos de todos esses anos de discriminação legal na vida da mulher, sobretudo no que se refere aos problemas nas relações de trabalho, visto que, apesar de não haver mais discriminação no plano formal, é necessário se alcançar a igualdade material.

Assim, nas últimas décadas, as mulheres têm ocupado massivamente o mercado de trabalho e o perfil dos cargos ocupados por elas tem se alterado. Isso se coloca como um desafio ao direito do trabalho, sobretudo para se alcançar a igualdade material com os homens em termos de igualdades de oportunidades e conciliação da vida familiar com a profissional (RAMALHO, 2003, p. 215-217).

Tradicionalmente, a figura do trabalhador em tempo integral, integrado à organização empresarial e sujeito do objeto da tutela dos direitos trabalhistas, é ocupada pelo homem, pai de família que provê o sustento doméstico. Isso porque, em países em que a mulher possui uma menor integração que o homem no mercado de trabalho, há a tendência das tarefas domésticas, sobretudo aquelas atinentes às atribuições familiares, como por exemplo o cuidado com os filhos, se perpetuarem como de responsabilidade da mulher. Nesse sentido, há uma melhor divisão das responsabilidades familiares quando há uma maior inserção das mulheres no mercado de trabalho de maneira paritária aos homens. Essa inserção massiva da mulher no mercado de trabalho se dá, muitas vezes, pela necessidade de complementação da renda familiar, ou seja, a mulher é praticamente compelida a disputar com homens os postos de trabalho, em nome do sustento de sua própria família. Assim, pode-se estabelecer a seguinte lógica: quanto mais igualdade material a mulher tiver nos postos de trabalho, maior será sua igualdade material nas divisões das responsabilidades domésticas. O contrário também é verdadeiro (RAMALHO, 2003, p. 218-220).

Para não se perder da mente o raciocínio inicialmente exposto acerca dos critérios de relevância das diferenças para o estabelecimento das igualdades, o que se busca demonstrar aqui é que, com a inserção massiva da mulher no mercado de trabalho, principalmente quando ela quer desempenhar profissões de mesma relevância 
que aquelas tradicionalmente desempenhadas por homens, o critério de sexo deixa de ser relevante para que socialmente haja uma diferença para a divisão dos trabalhos, domésticos ou não, entre homens e mulheres.

Quando não há uma repartição equitativa, para ambos, das responsabilidades pela conciliação da vida profissional e da vida familiar, existe um ponto de partida, ainda que não imediato, para a discriminação em razão do sexo. Assim, a existência de medidas que promovam somente a participação da mulher nas responsabilidades familiares, como é o caso da licença maternidade em período muito superior à licença paternidade, sem a previsão da licença parental no ordenamento jurídico, dificulta a redistribuição das responsabilidades pela conciliação da vida profissional com a familiar, o que na prática acaba privilegiando o homem, por ter mais tempo para dedicar-se profissionalmente que a mulher. Nesse sentido, é importante estabelecer uma relação direta entre a conciliação da vida profissional e familiar e o princípio de igualdade de tratamento entre trabalhadoras e trabalhadores (RAMALHO, 2003, p. 270272).

Essa desigualdade na divisão das responsabilidades extratrabalho funciona também como um teto de vidro que não permite a ascensão da mulher na carreira com o mesmo dinamismo com que o homem consegue progredir. Isso se justifica porque os homens conseguem dedicar-se quase que integralmente para sua vida profissional, ampliando as possibilidades para que cheguem aos altos cargos de gestão. Ademais, deve-se levar em consideração que as mulheres que conseguem chegar às posições mais elevadas nas empresas possuem, comumente, as mesmas "qualidades" dos homens (OLARTE, 2018, p. 175-185), ou seja, em oposição a tudo que se pretenda propor para uma inclusão da mulher no mercado de trabalho, por meio de uma mudança cultural e social, ainda se constata que as possibilidades das mulheres ascenderem na carreira aumentam quando elas passam a agir conforme os estereótipos masculinos, perpetuando-se o estigma sobre os estereótipos femininos.

Portanto, faz-se necessário o estabelecimento de medidas positivas para se promover o acesso da mulher ao mercado de trabalho e, ao mesmo tempo, para que a divisão histórica não se coloque como um empecilho a esse acesso, objetivando a compatibilização da vida no trabalho com a vida familiar (RAMALHO, 2003, p. 218220). Ocorre que há uma razão inversamente proporcional entre a implementação das ações afirmativas e a manutenção da igualdade formal, visto que essas ações mitigam a igualdade formal em busca da igualdade material. Essas ações afirmativas também são chamadas de ações de solidariedade e pode-se dizer, em algumas situações, que tais 
medidas visam atingir um bem, por meio de um mal. Isso porque, a exemplo das cotas, tira-se de uns para dar a outros supostamente mais necessitados. Assim, a necessidade de se buscar a implementação das medidas positivas, dado ao entrelaçamento do conceito de solidariedade com o conceito de igualdade, significa buscar uma sociedade mais solidária (PÉREZ LUÑO, 2007, p. 114-118).

Do ponto de vista discriminatório, pode-se dizer que há violência de gênero sempre que houver um comportamento de violência, moral ou não, motivado pelos estereótipos culturais e sociais, muitas vezes fazendo com que esses estereótipos se perpetuem. Como reflexo de um contexto social, essa violência também ocorre no ambiente do trabalho, sendo que sua manifestação mais caricata é identificada no assédio sexual. O assédio sexual, em poucas palavras e sem a pretensão de esgotar a complexidade dos atos que envolvem tal conduta, é caracterizado por atos de violência física ou verbal contra a vítima que contenham um caráter sexual (AROCHENA, 2014, p. 309-322).

Diferente do assédio sexual, tem-se o conceito de assédio sexista, que se caracteriza por qualquer comportamento em razão do sexo que pretenda criar um clima intimidatório, degradante ou ofensivo, ou ainda que tenha como objetivo atentar contra a dignidade da pessoa ofendida. A diferença entre ambos consiste na existência da natureza sexual e do ato físico ou verbal, quando se trata de assédio sexual, sendo que, ao se referir a assédio sexista, se estaria envolvendo todo assédio realizado em função do sexo. Ademais, o assédio sexista pode ocorrer de forma velada, em situações que ocultamente há o assédio por estereótipos culturais ou sociais, como por exemplo uma discriminação pela maternidade (AROCHENA, 2014, p. 322-327).

Nesse sentido, há assédio sexual ou sexista quando, em função dessas condutas, instaura-se uma discriminação para acesso ao emprego, para as condições de trabalho e também para a permanência no emprego. A existência dessas condutas de forma sistêmica e impregnada na estrutura empresarial, destinada à uma coletividade de trabalhadores, ou não, pode caracterizar assédio ambiental (AROCHENA, 2014, p. 327329), que, em última análise, além do direito à igualdade debatido neste artigo, fere também o direito fundamental dos trabalhadores a um meio ambiente do trabalho equilibrado, essencial à sadia qualidade de vida, nos termos do artigo 225 e 200, VIII da Constituição de 1988 (BRASIL, 1988).

Portanto, pode-se considerar como ponto de partida a existência de desigualdade entre homens e mulheres nas relações de trabalho, sendo as mulheres 
discriminadas, e, em alguns casos, essa discriminação chega a ser manifestada por meios mais violentos, como no caso dos assédios sexual e sexista.

\section{A NEGOCIAÇÃO COLETIVA COMO INSTRUMENTO DE EFETIVAÇÃO DA IGUALDADE DE GÊNERO}

A história das negociações coletivas de trabalho está intimamente relacionada com a história do sindicalismo, sendo que sua criação não decorreu das teorias jurídicas, mas das manifestações espontâneas da vida social. Essa prática deve ser incentivada pelo Estado, nos termos das Convenções 98 e 154 da OIT, ambas ratificadas pelo Brasil, e da Recomendação 163, também da OIT, sendo que uma liberdade sindical plena poderá fortalecer os sindicatos, favorecendo que eles desempenhem melhor sua função principal, as negociações coletivas (RIBEIRO; BARBOSA, 2013, p. 185-192).

O contexto de necessidade de liberdade sindical plena para sindicatos fortes e para negociações coletivas mais vantajosas para os trabalhadores pode levar a discussão para um ponto importante que chama a atenção e que não será objeto de estudo neste trabalho, mas será útil para uma continuidade do que se propõe pesquisar aqui.

O ponto que se refere é o da ultratividade das cláusulas normativas. Sobre essa ultratividade há, por uma parte da doutrina, a defesa de suas incorporações nos contratos individuais de trabalho, embasada no direito adquirido e na impossibilidade de alteração unilateral do contrato de trabalho em prejuízo do trabalhador. Por outro lado, há também, por outra parte da doutrina, a defesa plausível de que a impossibilidade de se voltar ao estado inicial inviabilizaria as negociações futuras de novas vantagens aos trabalhadores, pois prevaleceria o receio de não mais ser possível retroceder diante de uma legítima impossibilidade de continuar mantendo a situação mais vantajosa (RIBEIRO; BARBOSA, 2013, p. 185-200).

Como última observação sobre a ultratividade das cláusulas das negociações coletivas, coloca-se que mesmo a visão eclética acerca do tema, que defende a vigência destas cláusulas até que haja nova negociação coletiva (RIBEIRO; BARBOSA, 2013, p. 185-200), traz uma complicação em sua operacionalização, porque, respeitando-se o limite máximo de dois anos de vigência de uma negociação coletiva ou prorrogando sua vigência até que haja nova negociação, tem-se que essas cláusulas sempre deverão ser renegociadas, pois, em se concluindo que tais cláusulas não são permanentes, verificarse-ia a impossibilidade de se negociar direitos por prazo indeterminado, o que resultaria 
em desgaste para as partes e amarra à livre negociação coletiva (AROUCA, 2014, p. 7477).

Deixada de lado a questão acima, é importante para a investigação do presente artigo esclarecer que a Constituição de 1988 prevê a possibilidade de atuação do sindicato em favor dos interesses da categoria que representa, porém obriga a participação sindical nas negociações coletivas de trabalho, não permitindo que a entidade se omita quando provocada, o que se poderia pretender se fosse analisada somente a CLT (AROUCA, 1988, p. 51-54). Em que pese tal instrumento sindical eventualmente seja usado para precarização do trabalhado, colocando os trabalhadores em posição de maior opressão, as negociações coletivas, segundo o ordenamento jurídico brasileiro, deveriam ser instrumentalizadas para uma ampliação de direitos dos trabalhadores, visando uma melhora em sua qualidade de vida (RIBEIRO; BARBOSA, 2013, p. 183-185).

Nesse aspecto, o direito à negociação coletiva, previsto inclusive nas diretivas estabelecidas pela Organização Internacional do Trabalho - OIT, sobretudo na Convenção 87, ainda não ratificada pelo Brasil, é classificado como direito fundamental. Sua finalidade é proporcionar maior flexibilidade e agilidade para que as partes conflitantes no ambiente de produção - capital e trabalho - possam encontrar soluções customizadas para seus conflitos e assim apresentar uma melhor, e mais ágil, resposta que atenda a ambos interesses. Por esse ponto de vista, as negociações coletivas ganham ainda mais importância em um contexto capitalista globalizado, em que o Estado muitas vezes perde sua soberania para o avanço do capital estrangeiro e não é capaz de responder rapidamente aos avanços dos interesses desse capital sobre os interesses dos trabalhadores (RIBEIRO; BARBOSA, 2013, p. 183-185).

Nessa toada, cumpre-se a missão de dar ênfase ao mecanismo da negociação coletiva de trabalho que pode ter como objeto também a questão de igualdade entre os sexos. Essa missão não pretende, evidentemente, mitigar o fato das matérias relativas à igualdade de tratamento entre trabalhadores e trabalhadoras, em especial aquelas concernentes às medidas afirmativas ou protetivas que visem promover o tratamento igualitário entre ambos, poderem ser tratadas em âmbito internacional, constitucional e legislativo, principalmente porque o são. Porém, deve-se frisar que a negociação coletiva é um poderosíssimo instrumento que, quando bem utilizado, pode garantir melhoras nas condições de trabalho, principalmente quando se visa proteger a mulher (RAMALHO, 2003, p. 247-255). 
Outrossim, sem querer adentrar no mérito da validade constitucional, ou da extensão da validade, do artigo 611-A da CLT, ao se estabelecer a prevalência do negociado sobre o legislado (BRASIL, 2017), pois também não é o objetivo deste artigo, é importante frisar que a Constituição de 1988, por exemplo, prevê a expressa proibição de discriminação remuneratória em razão do sexo, no artigo $7^{\circ}, \mathrm{XXX}$. A lei maior prevê também a expressa proteção ao mercado de trabalho da mulher, mediante incentivos, nos termos do artigo $7^{\circ}, \mathrm{XX}$ (BRASIL, 1988). Ademais, o artigo 611-B, VX, da CLT, por exemplo, veda expressamente negociações coletivas de visem reduzir ou suprimir direitos relacionados à proteção do mercado de trabalho da mulher (BRASIL, 2017).

Os exemplos acima fazem concluir que a negociação coletiva de trabalho, quando versar sobre matérias relativas à busca pela igualdade material entre trabalhadores e trabalhadoras, deverá servir de instrumento para ampliação dessa igualdade, sobretudo pela previsão da possibilidade de outros direitos que visem à melhoria da condição social dos trabalhadores, constante na cabeça do artigo $7^{\circ}$ da Constituição de 1988 (BRASIL, 1988).

Assim, observa-se que no ordenamento jurídico brasileiro, a negociação coletiva é um instrumento apto a ampliar direitos sociais, incluindo a igualdade de gênero nas relações de trabalho.

\subsection{A NEGOCIAÇÃO COLETIVA E A IGUALDADE DE GÊNERO A PARTIR DO DIREITO COMPARADO}

Eva Tobías Olarte, em seu livro Equilíbrio de género em los consejos de administración de las empresas, comenta sobre a participação dos sindicatos no processo de implementação das medidas positivas visando a importância de uma legislação que incentive o envolvimento sindical nesses assuntos. Uma das medidas relevantes a ser adotada na busca pelo equilíbrio de gênero é a negociação coletiva de cláusulas de igualdade. Além das negociações coletivas, o sindicato pode atuar de maneira participativa na perseguição por esse equilíbrio, como no exemplo francês, em que se busca, por meio de políticas de incentivo à Responsabilidade Social Empresarial, implementar medidas positivas de igualdade. Para tanto, criou-se um comitê paritário entre Estado, sindicatos e representantes da classe empresária para a outorga de um selo de igualdade que atesta se determinada empresa promove a igualdade de gênero (OLARTE, 2018, p. 185-188). Em que pese o exemplo se passar em outro contexto, ele 
ressalta a importância do ordenamento jurídico, bem como sua hermenêutica, prezar por uma atuação sindical que amplie as conquistas sociais.

Assim, partindo-se das premissas de que as negociações coletivas são importantes instrumentos para a efetivação da igualdade material entre trabalhadores e trabalhadoras, bem como que, no ordenamento jurídico pátrio, as negociações coletivas de trabalho não podem, em tese, ser instrumentalizadas para gerar mais desigualdades materiais em razão do sexo, faz-se de grande importância estabelecer como esses direitos poderiam ser contemplados nesses instrumentos normativos com a finalidade de efetivar a tão debatida igualdade material em razão do sexo nas relações de trabalho.

Diante disso, o problema discriminatório trazido por condutas de assédio sexual ou assédio sexista podem ser tratados nas negociações coletivas com o estabelecimento "de cláusulas conceituais, declarações de princípios, solução informal, sanção disciplinatória e garantias de procedimento" (AROCHENA, 2014, p. 334-335).

Ademais, apropriando-se de uma metodologia espanhola para a implementação de medidas protetivas que promovam a igualdade de gêneros nos contratos administrativos, acredita-se que as negociações coletivas possam se valer dos objetivos semelhantes aos defendidos para aquelas medidas, quais sejam, "a promoção da igualdade entre homens e mulheres e medidas de conciliação entre a vida laboral e familiar, dentre outros" (OLARTE, 2018, p. 189-192). Onde se pretende chegar com essa lógica é que as partes, sobretudo os sindicatos, ao irem para uma negociação imbuídos de um espírito que busque a efetivação dessa igualdade, poderiam chegar às soluções pontuais com uma facilidade e eficácia maior que a de um processo legislativo.

Uma das cláusulas que podem ser negociadas é a previsão de isonomia em demissões, sobretudo nas coletivas, de forma a não prejudicar as mulheres em momentos de crises em razão de estereótipos sociais e culturais (OLARTE, 2018, p. 228-229). Há também a possibilidade de, em negociações coletivas, serem estabelecidas cláusulas que garantam a participação sindical no desenvolvimento de programas de Responsabilidade Social Empresarial, para que, por meio desses, também sejam propostos indicadores de gestão que garantam a transparência de critérios de seleção e promoção, com a finalidade de proporcional igualdade entre homens e mulheres, sobretudo no acesso ao emprego e na ascensão na carreia dentro das empresas (OLARTE, 2018, p. 142-148).

Assim, no âmbito das negociações coletivas, para que elas colaborem com a efetivação da igualdade entre trabalhadores e trabalhadoras e com isso sirvam de medidas afirmativas em favor da igualdade de gênero, é importante que existam 
cláusulas que estabeleçam modelos justos de "contratação, formação, promoção profissional, qualificação, classificação, condições de trabalho, seguridade e saúde, remuneração e conciliação da vida profissional e familiar", de modo que ambos gêneros tenham iguais condições nas relações de trabalho (OLARTE, 2018, p. 169-170).

Portanto, vê-se que há exemplos no direito comparado de busca de igualdade de gênero nas relações de trabalho por meio da atuação sindical, bem como, é possível identificar cláusulas com potencial de contribuição na igualdade de gênero nas relações de trabalho nos instrumentos que resultam das negociações coletivas.

\section{A NEGOCIAÇÃO COLETIVA A PARTIR DA CATEGORIA DOS PROFESSORES NO ESTADO DO PARANÁ}

A partir da hipótese teórica apresentada, em que se verifica não só a possibilidade, mas também a necessidade, dos sindicatos se envolverem na busca pela efetivação da igualdade material entre trabalhadores e trabalhadoras (OLARTE, 2018, p. 148-149), propõe-se uma análise empírica das negociações coletivas envolvendo o Sindicato dos Professores no Estado do Paraná, cujos dados estão disponíveis no site do Ministério da Economia, Secretaria Especial de Previdência e Trabalho e que foram obtidos por meio de consulta à plataforma eletrônica Sistema de Negociações Coletivas de Trabalho - MEDIADOR.

A busca limitou-se às negociações coletivas envolvendo o Sindicato dos Professores no Estado do Paraná, por se tratar de pesquisa acadêmica e por esse sindicato representar a classe de professores empregados. Além disso, há uma íntima relação entre aqueles que já são ou pretendem ser professores, e por isso dedicam-se à pesquisa acadêmica, e a parte envolvida no objeto desta pesquisa, o representante dessa classe nas negociações coletivas. Ademais, por se tratar de um artigo científico e não representar uma pesquisa demasiada extensa, limita-se a descrever quais direitos foram encontrados nas negociações, abstendo-se, portanto, de relacionar quais são as negociações e suas cláusulas. Por fim, a busca limitou-se aos instrumentos coletivos registrados no Ministério da Economia, Secretaria Especial de Previdência e Trabalho, que vigeram durante o ano de 2019, sendo apresentada a totalidade dos registros retornados na consulta à plataforma com o CNPJ 76.687.920/0001-91, que vigeram durante o período de 01/01/2019 a 01/01/2020, visto que a análise está relacionada aos avanços perante a lei.

Assim, a pesquisa não tem o condão quantitativo, mas sim qualitativo, pois pretende investigar se as negociações coletivas do Sindicato dos Professores no Estado 
do Paraná contribuíram para a efetivação da igualdade entre trabalhadores e trabalhadoras no ano de 2019.

\subsection{AVANÇOS E RETROCESSOS}

Em suma, identificou-se cláusulas que repetem direitos já previstos em lei e que podem contribuir para a igualdade de gênero nas relações de trabalho, ainda que de forma indireta, notadamente o direito à creche, à jornada especial durante o período de amamentação, à licença-maternidade e licença-adoção, à estabilidade da gestante e da adotante.

Também foram identificadas algumas ampliações de direitos que têm potencial contributivo para a igualdade de gênero nas relações trabalhistas por proporcionarem uma melhor conciliação entre a vida profissional e vida familiar, tais como a ampliação do tempo da licença-maternidade, do tempo de amamentação e o pagamento de auxíliocreche.

Dentre os dados analisados, observou-se também ampliações de direitos que, além do potencial de melhorar a conciliação entre a vida profissional e vida familiar, podem contribuir para distribuição paritária das responsabilidades domésticas, como a flexibilização de ausências no trabalho, de horários e a redução de jornada, o que favorece a igualdade entre trabalhadores e trabalhadoras.

Ainda no que se refere à possibilidade de distribuição paritária das responsabilidades domésticas, identificou-se o direito à ampliação da licença paternidade.

Ademais, identificou-se cláusula que combate o estigma social que envolve as mulheres, e, portanto, também pode contribuir para a igualdade de gênero nas relações de trabalho, sendo ela a estabilidade ao empregado que se torna pai.

Identificou-se também cláusula expressa de licença remunerada para a empregada vítima de violência doméstica, que possui potencial contributivo para a igualdade de gênero nas relações de trabalho, visto favorecer o combate à violência doméstica.

Por fim, foram detectadas duas cláusulas que restringem os direitos das adotantes.

\section{CONSIDERAÇÕES FINAIS}


No presente artigo define-se a igualdade e demonstra a necessidade de se evitar a discriminação dos trabalhadores em razão do sexo por meio da efetivação da igualdade entre trabalhadores e trabalhadoras.

Demonstra-se também que as negociações coletivas podem ser um poderoso instrumento na busca pela igualdade material entre trabalhadores e trabalhadoras, bem como, um igualmente poderoso instrumento de combate à discriminação em razão do sexo e ao assédio sexual.

Assim, a partir dessas constatações teóricas, analisou-se as contribuições das negociações coletivas realizadas pelo Sindicato dos Professores no Estado do Paraná como medida e efetivação da igualdade entre trabalhadores e trabalhadoras.

Das negociações analisadas, não foi possível constatar um enfrentamento direto da questão da igualdade, sendo que em nenhuma delas constaram objetivos de se elaborar planos de RSE com a previsão de transparência e metas de efetivação de igualdade. Também não foram observadas cláusulas que estabelecessem a necessidade de igualdades salariais, ou paridade na ocupação dos postos de trabalho e ascensão nas carreiras. Não foram encontradas também cláusulas de prevenção e de punição para assédios sexuais ou de discriminação em razão do sexo no ambiente do trabalho.

Porém, foram identificadas reproduções de direitos previstos em leis, ampliações de direitos e, até mesmo, restrições de direitos.

No entanto, em que pese muitos dos direitos identificados não serem dirigidos exclusivamente às mulheres, acredita-se que tais normas contribuam para a efetivação da igualdade, pois facilitam a conciliação da vida profissional com a vida familiar. Além disso, considerando que a sociedade ainda sofre o reflexo da divisão desigual das responsabilidades domésticas entre homens e mulheres, sendo essa uma das causas de desigualdade de gênero nas relações de trabalho, as normas facilitadoras dessa conciliação servem tanto para garantir que as empregadas que eventualmente carreguem a maioria das responsabilidades domésticas sozinhas possam ter acesso ao trabalho, quanto para proporcionar uma oportunidade para que os empregados passem a assumir mais responsabilidades domésticas dada a facilidade encontrada em seus empregos, frente à eventual rigidez nos empregos de seus cônjuges, e desta forma, gradualmente, contribuam para uma mudança do contexto social que interfira na desigualdade nas relações de trabalho.

Também acredita-se ser de bom-tom aquelas cláusulas que se limitam a repetir as disposições legais, pois além de chamar a atenção para a importância do tema, sempre há a possibilidade de uma alteração legislativa mal debatida e sem a 
participação efetiva dos representantes dos empregados para a defesa de seus interesses, que pode ser conduzida com atropelo e pressa, na tentativa de fragilizar a classe trabalhadora e fortalecer a classe empregadora. Nessa hipótese, é importante que o sindicato já tenha debatido o tema e lute por, pelo menos, um não retrocesso em direitos que favoreçam a igualdade efetiva entre trabalhadores e trabalhadoras.

Por fim, em que pese tenha se encontrado duas cláusulas que restrinjam os direitos das adotantes, a intepretação hermenêutica segundo a lógica do ordenamento jurídico pátrio deve garantir que as mulheres adotantes tenham seus direitos garantidos em lei respeitados. No entanto, essa constatação mostra uma fragilidade na luta sindical da classe quanto ao tema, pois demonstra uma incapacidade de o sindicato conseguir manter em um acordo coletivo direitos já previstos em lei, podendo se transformar em um problema ainda mais grave em caso de alteração legislativa e constitucional.

Assim, apesar de incipiente e de haver bastante espaço para melhora, pode-se concluir que, de uma maneira geral, o sindicato analisado contribui com a efetivação da igualdade entre trabalhadores e trabalhadoras, principalmente no que diz respeito à ampliação de direitos que possibilitem a conciliação entre a vida profissional e a vida familiar das trabalhadoras, a paridade das divisões das responsabilidades domésticas e a proteção da mulher contra a violência doméstica. 


\section{REFERÊNCIAS}

AROCHENA, José Fernando Lousada. El derecho fundamental a la igualdad efectiva de mujeres y hombres. Valência: Tirant to Blanch, 2014.

AROUCA, José Carlos. A nova constituição e os trabalhadores. São Paulo: Sindicato dos trabalhadores nas indústrias da Construção Civil de São Paulo, 1988.

AROUCA, José Carlos. As Perspectivas do Direito Coletivo do Trabalho. Revista Síntese Trabalhista e Previdenciária. v. 24, n. 299. São Paulo: Síntese, 2014. p. 6583.

ÁVILA, Humberto. Teoria dos princípios: da definição à aplicação dos princípios jurídicos. 2. ed. São Paulo: Malheiros Editores, 2003.

BRASIL. Constituição (1988). Constituição: República Federativa do Brasil. Brasília, DF: Senado Federal, 1988. Disponível em <http://www.planalto.gov.br/ccivil_03/constituicao/constituicao.htm>. Acesso em: 28 mai. 2019.

BRASIL. Lei no 8.213 de 1991. Dispõe sobre os Planos de Benefícios da Previdência Social e dá outras providências. Texto consolidado. Diário Oficial da União, Brasília, DF, 25 jul. $\quad 1991 . \quad$ Disponível em http://www.planalto.gov.br/ccivil_03/leis/18213cons.htm>. Acesso em: 25 jun. 2019.

BRASIL. Lei n ${ }^{\circ} 13.467$ de 2017. Altera a Consolidação das Leis do Trabalho (CLT), aprovada pelo Decreto-Lei no 5.452, de 1o de maio de 1943, e as Leis nos 6.019, de 3 de janeiro de 1974, 8.036, de 11 de maio de 1990, e 8.212, de 24 de julho de 1991, a fim de adequar a legislação às novas relações de trabalho. Diário Oficial da União, Brasília, $\quad$ DF, 14 jul. 2017. Disponível em <http://www.planalto.gov.br/ccivil_03/_ato2015-2018/2017/lei/113467.htm>. Acesso em: 06 jun. 2019.

GEARA; Diana Maria Palma Karam Geara; BOTH, Laura Garbini. O protagonismo feminino na democratização das relações familiares. In: FREITAS, Héliomar Jerry 
Dutra de (Org.); CORDIOLLI, Marcos (Coord.); SÉLLOS-KNOER, Viviane Coêlho de (Dir.) Cultura \& inclusão. Curitiba: Instituto Memória, 2016.

MARTINEZ, Maria Salvador. Las medidas de acción positiva. Princípio de igualdady y derechor fundamentales. In: GONZALEZ, Santiago Sanchez (Coord.). En torno a la igualdad y a la desigualdade. Madrid: Dykinson, 2009. p. 29-54.

OLARTE, Eva Tobías. Equilíbrio de género em los consejos de administración de las empresas. Pamplona: Editorial Aranzadi, 2018.

PÉREZ LUÑO, Antonio Enrique. Dimensiones de la igualdad.2. ed. Madrid: Dykinson, 2007.

RAMALHO, Maria do Rosário Palma. Estudos de Direito do Trabalho. Lisboa: Almedina, 2003. p. 215-277.

RIBEIRO, Luiz Alberto Pereira; BARBOSA, Renato Lima. Negociação coletiva de trabalho: de direito fundamental a instrumento de precarização. In: CAVALCANTE, Jouberto de Quadros Pessoa (Coord.); VILATORE, Marco Antônio César (Coord.). CLT: 70 anos de consolidação: uma reflexão social econômica e jurídica. São Paulo: Atlas, 2013. p. 183-204.

VILLATORE, Marco Antônio César; GUNTHER, Luiz Eduardo. GLOBALIZATION, ECONOMIC CRISIS AND COLLECTIVE BARGAINING IN INTERNATIONAL LABOR LAW. Revista Juridica, [S.1.], v. 51, n. 2, p. 137 - 165, abr. 2018. ISSN 2316-753X. Disponível em: <http://revista.unicuritiba.edu.br/index.php/RevJur/article/view/2803/371371471>. Acesso em: 19 abr. 2020. doi:http://dx.doi.org/10.21902/revistajur.2316753X.v51i2.2803. 